\title{
EFSUMB AWARDS AT EUROSON 2019
}

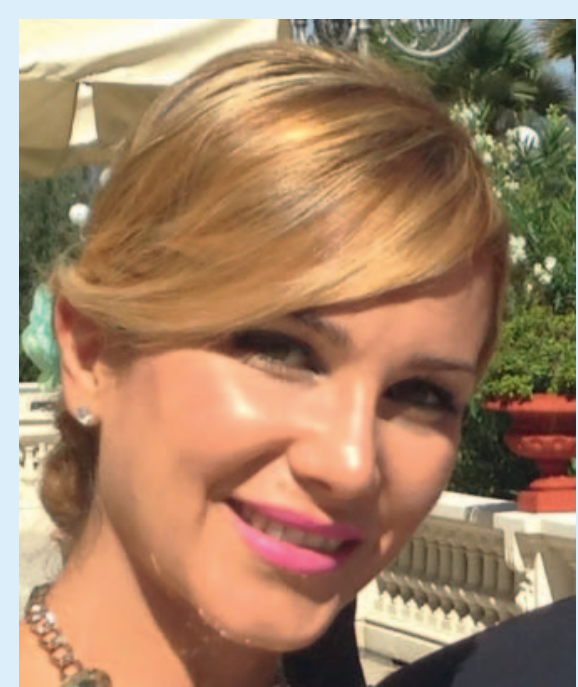

The EFSUMB Best Published Paper 500 euro Prize was awarded to Eleanore Terzi, Italy for the paper Contrast ultrasound LI-RADS $L R$-5 identifies hepatocellular carcinoma in cirrhosis in a multicenter retrospective study of 1,006 nodules published http://dx.doi.org/ 10.1016/j.jhep.2017.11.007

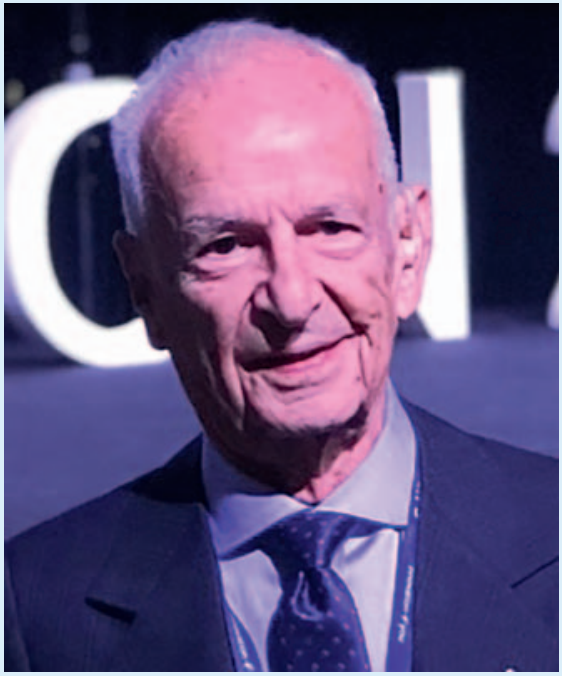

Congratulations to Prof Hadi Ozer, Turkey who was elected EFSUMB newest Honorary Member.

In the field of ultrasound, Prof. Ozer, Professor of Radiology, is the pioneer in Turkey and one of the pioneers in the United States, as well. Born 1927 he enjoys good health and is still active in the world of ultrasound. In 2018 he gave a lecture in Poznan about the history of ultrasound in USA and Turkey.

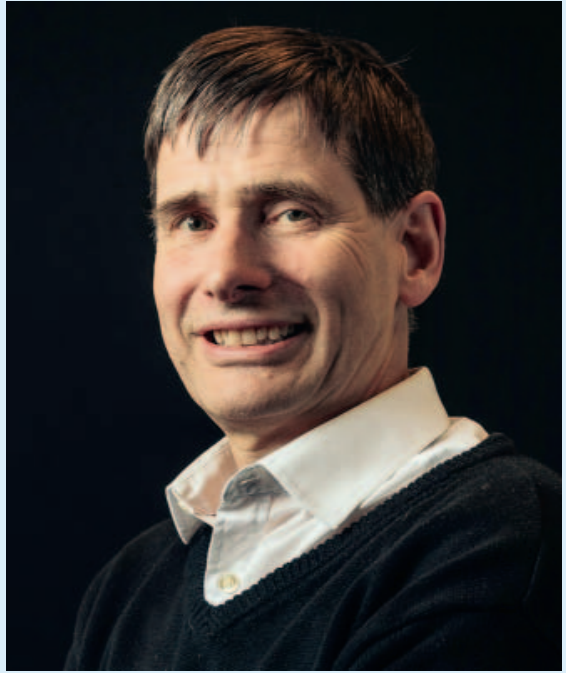

Congratulations also to Nico de Jong, The Netherlands, elected as an EFSUMB Fellow for his career spent on the clinical development and translation of contrast agents for ultrasound. 